\title{
Medical students' perspectives on learning preferences within clinical settings
}

This article was published in the following Dove Press journal:

Advances in Medical Education and Practice

\author{
Fahad Mohammad \\ Aniruddh Shenoy \\ College of Medical and Dental \\ Sciences, University of Birmingham, \\ Birmingham, UK
}

Correspondence: Fahad Mohammad College of Medical and Dental Sciences, University of Birmingham, Edgbaston, Birmingham BI5 2TT, UK

Email fxm362@student.bham.ac.uk

\section{Dear editor}

We read with great interest the study by Caton et $\mathrm{al}^{1}$ regarding residents and their perceptions surrounding which learning experiences serve as the most effective. While the American residency program equates to the British foundation program, such insights are hugely pertinent to us as final-year medical students who are starting the third term of hospital attachments before beginning the house jobs. Furthermore, as students who already have 2 years of experience in a hospital setting, we have experienced various learning opportunities, some of which are echoed in this study. As such, we hope our personal reflections will further elucidate some of these findings.

Resonating with us heavily was the fact that $36 \%$ of the participants agreed that having a "co-resident" involved in their learning experience was a valuable factor. Our medical course actually includes a mandatory module where each student leads a formal teaching session to peers. Feedback from these sessions validates that peer teaching is invaluable and this is further substantiated by $\mathrm{Yu}$ et $\mathrm{al}^{2}$ in their systematic review. We believe this is secondary to peers being able to pitch better at a level and pace which tutees are more comfortable with.

Second and perhaps more important, students at the same level may have higher levels of active engagement (a key theme in this study), perhaps as a result of being more comfortable asking questions or engaging in discussions with those who are at the same stage in their career.

More surprising, however, was how only $12 \%$ of the participants responded that the patient's bedside was where valuable learning occurred. From personal experience, we find bedside teaching to be an extremely effective teaching tool as has been validated by Nair et $\mathrm{al}^{3}$ alongside anecdotal agreement within our cohort. We hypothesized that this could be due to differences in the way British and American doctors instruct during bedside teaching sessions and that this variation may be secondary to differences in cultural traits. For example, a country with less extraversion or openness may prefer to engage less in bedside teaching as a result of their hesitation in dealing with uncertainty, ie, patient variation in the case of bedside teaching. However, Kajonius and Mac Giolla ${ }^{4}$ showed that UK and USA are almost the same in their cultural characteristics. Thus, these differences may be due to other factors, institutional or others.

Nevertheless, we share the position this paper takes in that the perspective students have of their learning experience is vital toward evolving their education as future 
health care practitioners. It is understandable that within any cohort there will inevitably be a range of learning strategies that are found to be effective. However, with limited resources and time constraints, it may be a case of finding those which engage a majority of the cohort and offer more specialized methods outside of routine hours to those who would especially benefit from them.

\section{Disclosure}

The authors report no conflicts of interest in this communication.

\section{References}

1. Caton JB, Pelletier SR, Shields HM. Asking what do residents value most: a recent overview of internal medicine residents' learning preferences. Adv Med Educ Pract. 2018;9:509-518.

2. Yu TC, Wilson NC, Singh PP, Lemanu DP, Hawken SJ, Hill AG. Medical students-as-teachers: a systematic review of peer-assisted teaching during medical school. Adv Med Educ Pract. 2011;2:157-172.

3. Nair BR, Coughlan JL, Hensley MJ. Student and patient perspectives on bedside teaching. Med Educ. 1997;31(5):341-346.

4. Kajonius P, Mac Giolla E. Personality traits across countries: Support for similarities rather than differences. PLoS One. 2017;12(6):e0179646. 


\section{Authors' reply \\ Julia B Caton' \\ Stephen R Pelletier ${ }^{2}$ \\ Helen M Shields'}

'Brigham and Women's Hospital, Harvard Medical School, Boston, MA, USA; ${ }^{2}$ Center for Evaluation, Harvard Medical School, Boston, MA, USA

Correspondence: Helen M Shields

Brigham and Women's Hospital,

Harvard Medical School, 75 Francis

Street, Boston, MA 02115, USA

$\mathrm{Tel}+\mathrm{l} 6175259315$

Email hmshields@bwh.harvard.edu

\section{Dear editor}

We appreciate the thoughtful comments we received from Fahad Mohammad and Aniruddh Shenoy, two medical students at the College of Medical and Dental Sciences, University of Birmingham, Birmingham, UK, regarding our article "Asking what do residents value most: a recent overview of internal medicine residents learning preferences". ${ }^{1}$

We agree that peer-to-peer learning is an important educational modality and might serve to foster resident engagement in learning experiences. As you highlight, 36\% of the residents surveyed in our study reported that their most valuable learning experience of the day involved a co-resident, these experiences not only encompassed formal peer-to-peer teaching, as described in Yu et al's ${ }^{2}$ review of medical student peer teaching, but also included informal learning experiences surrounding caring for a patient in the clinical setting.

We also recognize that bedside learning is an essential component of the education of physicians. As you note, bedside teaching, when executed well, has been shown to be an effective teaching modality. For example, this was recently shown in Perez et al' $\mathrm{s}^{3}$ study using the patient as a co-teacher on rounds. However, not all studies support this finding. For example, Gonzalo et $\mathrm{al}^{4}$ found at their institution that house staff participating in bedside rounds were less likely to report that bedside rounds were more educational compared with non-bedside rounds. We postulate that findings such as those of Gonzalo et al, as well as our own findings, do not diminish the importance of bedside learning. Rather, they demand that we scrutinize and optimize current educational practices at the bedside, including involving the patient.

We hope that our study will be a jumping-off point for future studies that explore best practices for taking resident engagement to a superior level by involving the patient as a key educator.

\section{Disclosure}

The authors report no conflicts of interest in this communication.

\section{References}

1. Caton JB, Pelletier SR, Shields HM. Asking what do residents value most: a recent overview of internal medicine residents' learning preferences. Adv Med Educ Pract. 2018;9:509-518.

2. Yu TC, Wilson NC, Singh PP, Lemanu DP, Hawken SJ, Hill AG. Medical students-as-teachers: a systematic review of peer-assisted teaching during medical school. Adv Med Educ Pract. 2011;2:157-172.

3. Perez AA, Pelletier SR, Klein IA, Shields HM. Patient as co-teacher on rounds: a pilot study. J Gen Intern Med. 2018;33(7):1010-1012.

4. Gonzalo JD, Chuang CH, Huang G, Smith C. The return of bedside rounds: an educational intervention. J Gen Intern Med. 2010;25(8): 792-798.

Dove Medical Press encourages responsible, free and frank academic debate. The content of the Advances in Medical Education and Practice 'letters to the editor' section does not necessarily represent the views of Dove Medical Press, its officers, agents, employees, related entities or the Advances in Medical Education and Practice editors. While all reasonable steps have been taken to confirm the content of each letter, Dove Medical Press accepts no liability in respect of the content of any letter, nor is it responsible for the content and accuracy of any letter to the editor.

\section{Publish your work in this journal}

Advances in Medical Education and Practice is an international, peerreviewed, open access journal that aims to present and publish research on Medical Education covering medical, dental, nursing and allied health care professional education. The journal covers undergraduate education, postgraduate training and continuing medical education including emerging trends and innovative models linking education, research, and health care services. The manuscript management system is completely online and includes a very quick and fair peer-review system. Visit http://www.dovepress.com/testimonials.php to read real quotes from published authors. 